\title{
Composition of Carotenoids in Scenedesmus protuberans: Application of Chromatographic and Spectroscopic Methods
}

\author{
Ayșegül Erdoğan • Ali Çağır • Meltem Conk Dalay • \\ Ahmet E. Eroğlu
}

Received: 22 October 2014 / Accepted: 5 January 2015 /Published online: 16 January 2015

(C) Springer Science+Business Media New York 2015

\begin{abstract}
This study aimed to identify and determine the carotenoids from green microalga, Scenedesmus protuberans using analytical techniques. Identification of carotenoids was realized by comparing their absorption and mass spectral data with those of reference standards available and reported values. Chromatographic data were then combined with the spectroscopic information. The separation of carotenoids was achieved by $\mathrm{C}_{30}$ column and high-performance liquid chromatography-diode array detection was used for their determination. In the present work, the carotenoid content of $S$. protuberans was found to be $1.45 \mathrm{mg} / \mathrm{g}$ of violaxanthin, $2.47 \mathrm{mg} / \mathrm{g}$ of all-trans-lutein, $0.15 \mathrm{mg} / \mathrm{g}$ of all-trans- $\alpha$-carotene, $0.55 \mathrm{mg} / \mathrm{g}$ of all-trans $-\beta$-carotene, and $0.20 \mathrm{mg} / \mathrm{g}$ of 9 or 9 '-cis- $\beta$-carotene. Due to lack of their standards, the amount of all-trans-loroxanthin and cis-isomers of other carotenoids could not be quantified. In order to validate the method, Certified Reference Material (BCR 485-Mixed vegetables) was used. In conclusion, this study can serve as a reference for the analysis of carotenoids in other microalgae.
\end{abstract}

Keywords Scenedesmus protuberans · Extraction . Carotenoids · Method validation · Chromatography and spectroscopy

\footnotetext{
A. Erdoğan $(\bowtie) \cdot$ A. Çağır $\cdot$ A. E. Eroğlu

Department of Chemistry, İzmir Institute of Technology,

Urla 35430, İzmir, Turkey

e-mail: aysegul_erdogan@live.com

A. Çağır

e-mail: alicagir@iyte.edu.tr

A. E. Eroğlu

e-mail: ahmeteroglu@iyte.edu.tr

M. C. Dalay

Department of Bioengineering, Ege University,

Bornova 35100, İzmir, Turkey

e-mail: meltemconkdalay@gmail.com
}

\section{Introduction}

There has been considerable attention for the isolation of bioactive compounds from marine resources, and microalgae play a significant role among them (Christaki et al. 2012). The microalga can be simply described as an organism that is small, generally unicellular, and found mainly in water. They are reported to be colorful due to their photosynthetic and some other pigments (Olaizola 2003). They contain many substances like fatty acids, tocopherols, vitamins, antioxidants, and pigments (Andersen 2005). These could be alternative neutraceuticals. One of the main important advantages of microalgae is their rapid growth over traditional plants (Spolaore et al. 2006). Probably, the most promising aspect of microalgal biotechnology is to develop microalgal products that have pharmaceutical properties (Borowitzka 1995).

Carotenoids are reported to be synthesized by plants and microorganisms but not the animals (Rao and Rao 2007). Carotenoids are liphophilic substances that are chemically classified in two groups: carotenes and xanthophylls (Britton et al. 2004). They are known to have the ability to quench singlet oxygen due to their conjugated double bond system. For this reason, carotenoids are powerful antioxidants, and they can lower the risk of developing certain human diseases like cardiovascular diseases, cancer, and age-related macular degeneration (Fraser and Bramley 2004; Kotake-Nara and Nagao 2011; Maiani et al. 2009).

Due to an extensive conjugated polyene chain, carotenoids show yellow, orange, and red colors. They have absorption maxima in the range of 400-500 $\mathrm{nm}$. Therefore, carotenoids can exhibit unique molecular shape, chemical reactivity, and light-absorbing properties. The positions of the absorption maxima and the shape or fine structure of the ultravioletvisible (UV-vis) spectrum are characteristic (Landrum 2010). The differences in the spectral characteristics of individual carotenoids are often small but are of great importance 
in their identification. Based on these features, highperformance liquid chromatography (HPLC) using absorbance detectors are widely used. They can determine carotenoid profiles both qualitatively and quantitatively. However, many carotenoids are structurally similar. For this reason, it has been stressed that UV-vis spectrum alone is not sufficient to characterize a carotenoid but provides information about the chromophore (Britton 1995a). Therefore, identification of carotenoids using other detection methods is required. Among those, mass detectors have shown great advantages for the analysis of these substances, including the elucidation of their structure based on the molecular mass and their fragmentation pattern. The use of mass spectrometry (MS) data has been an important chemical approach to structure elucidation (Rivera and Canela-Garayoa 2012; Sivathanu and Palaniswamy 2012; van Breemen et al. 2012). Finally, the retention times of the carotenoid standards should be compared with those of carotenoids that are tentatively identified.

It can be said that carotenoid research is a multidisciplinary area that many researchers work like analytical chemists, organic chemists, food chemists, biologists, physiologists, medical doctors, and environmentalists. It shows that great demands have been placed on their identification and determination (Ladislav et al. 2005). Carotenoid analysis is a complex task, and therefore, new, fast, and easily applicable procedures must be developed. In addition, it has been emphasized that their identification and quantification require highly sensitive and selective analytical methods (Carmona et al. 2003; Inbaraj et al. 2008; Maoka et al. 2002; Rehbein et al. 2007; Tian et al. 2003; Van Breemen 1997).

Moreover, an important problem in carotenoid analysis lies in the unavailability of standard carotenoid compounds. In these past few years, more carotenoid standards have become available; however, their prices are extremely high, as they are unstable. For this reason, it has been thought that accumulated carotenoids in microalgae can also be an alternative source for standards apart from their roles in diseases.

The goal of this work was to identify and determine the concentration of carotenoids produced by selected microalga (Scenedesmus protuberans) from EGE-MACC (EgeMicroalgae Culture Collection). As photosynthetic organisms, all algae contain chlorophylls and carotenoids. Algal carotenoids exhibit wide structural diversity. Carotenoids are found in algae, and recently, taxonomic studies of algae have been developed. Many different kinds of carotenoids were found from the algal species studied. Some carotenoids are found only in some algal divisions or classes. The most important sources of microalgae are Chlorella, Chlamydomonas, Dunaliella, Muriellopsis, and Haematococcus spp, all of which belong to the Chlorophyceae family. Different types of carotenoids are present in these biomasses, and they are synthesized under certain cultivation conditions. Scenedesmus is also a genus of algae, specifically of the Chlorophyceae
(Guedes and Amaro 2011; Takaichi 2011). S. protuberans, being a type of Chlorophyceae, is a novel one whose carotenoid content has not been studied yet in literature. That is why this microalga has been selected in the present study. The identification of carotenoids in S. protuberans was done using chromatographic/spectroscopic techniques. Their quantification was achieved by high-performance liquid chromatography-diode array detection (HPLC-DAD) using commercially available carotenoid standards.

\section{Materials and Methods}

\section{Chemicals}

All-trans-lutein, all-trans-violaxanthin, all-trans-neoxanthin, all-trans- $\beta$-carotene, all-trans- $\alpha$-carotene, 9 or 9 '-cis- $\beta$-carotene, and trans- $\beta$-apo- 8 '-carotenal were provided by CaroteNature (Switzerland) while triethylamine, and pyrogallol were purchased from Sigma-Aldrich. All the solvents used in this study were HPLC-grade obtained from Merck.

\section{Cultivation and Preparation of S. protuberans}

S. protuberans was obtained from the culture collection of Ege University Microalgae Culture Collection (Ege-MACC). It was obtained from Lake Eğridir in TURKEY and isolated by streak plate method. After that, it was grown in Bold's Basal Medium (Fabregas et al. 2000) under constant light (2, $0001 \times)$ and temperature $\left(25 \pm 1{ }^{\circ} \mathrm{C}\right)$ since $S$. protuberans grows very quickly in this selected medium.

The microalgal cells in 2.0-L bottles were illuminated with the continuous light of $2,000 \mathrm{lux}$ at $25.0^{\circ} \mathrm{C}$. Ventilation rates were $1.25 \mathrm{vvm}$. Cultures were prepared from $10 \%$ inoculation from a stock of 4-day $10 \%$ inoculation. Illumination was provided by using cool white fluorescent lamps (Philips, $18 \mathrm{~W} / 54)$. All glassware and the medium were sterilized in an autoclave at $121.0^{\circ} \mathrm{C}$ for $20.0 \mathrm{~min}$ prior to use.

When the microalgal cells were ready for harvesting, they were filtered by $0.45-\mu \mathrm{m}$ cellulose acetate filter paper and washed with deionized water to remove the growing medium. Harvested cells were then lyophilized and stored at $-20^{\circ} \mathrm{C}$ for one night. After this process was completed, they were grounded using a mortar to reduce their size for extraction process. The morphology of this green microalga used in this study can be examined from Fig. 1 .

\section{Identification of S. protuberans}

Microscopic and scanning electron microscope (SEM) analyses allowed preliminary identification of S. protuberans. Optical image was obtained under a trinocular light microscope (Olympus CH40, Japan). SEM characterizations were carried 

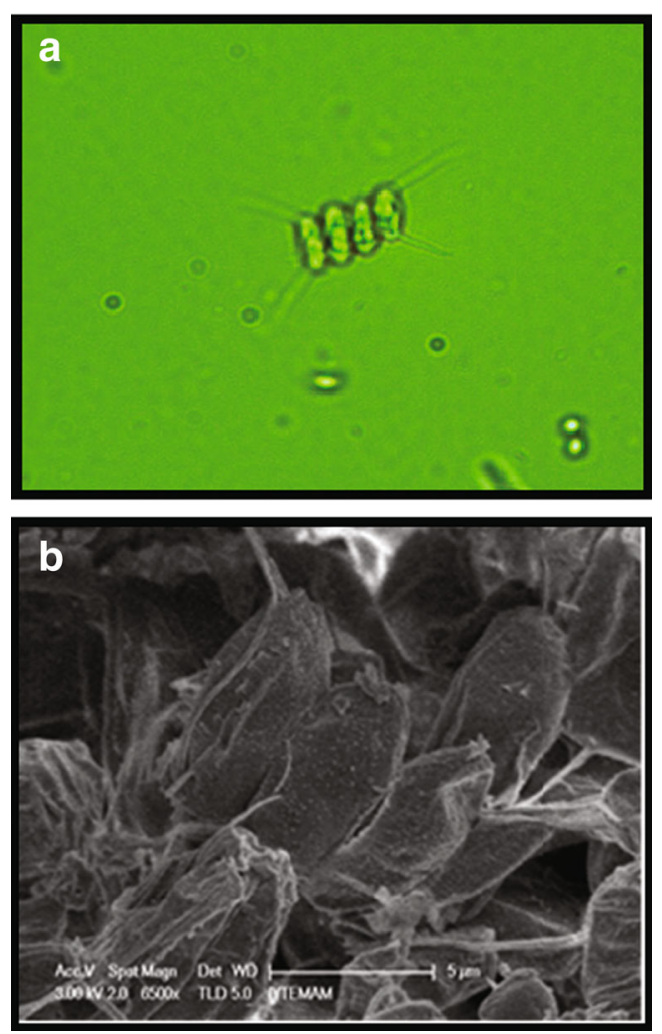

Fig. 1 a Optical image $(\times 40)$ and b SEM image $(\times 6,500)$ of S. protuberans

out using Philips XL-30S FEG (Holland). Moreover, the elemental composition of the microalga was determined with LECO-932 (USA) elemental analyzer.

\section{Extraction of Carotenoids from S. protuberans}

For the extraction of carotenoids from S. protuberans, a simple ultrasound-assisted extraction method was developed by using $37 \mathrm{kHz}$ ultrasonic bath (Elmasonic $\mathrm{S} 80 \mathrm{H}$ ) with a power of $200 \mathrm{~W}$. Then, the solvents were removed with the use of rotary evaporator (Heidolph Hei-VAP Advantage, Germany). Each microalgal powder $(0.25 \mathrm{~g})$ was added $\mathrm{CaCO}_{3}(0.25 \mathrm{~g})$ and extracted with $10.0 \mathrm{~mL}$ of THF/DCM (1:1) containing $0.010 \%(w / v)$ pyrogallol. The mixture was placed in the ultrasonic bath for $15.0 \mathrm{~min}$. After the ultrasonic extraction, the solution was centrifuged at $6,000 \mathrm{rpm}$ for $10 \mathrm{~min}$, and the supernatant was collected. The residue was repeatedly extracted with $10.0 \mathrm{~mL}$ extraction solvent until it was colorless. The supernatants were combined and evaporated by the rotary evaporator at $35.0{ }^{\circ} \mathrm{C}$ under vacuum. For the determination of carotenoids in green microalga, the extraction procedure was followed by the 2-h saponification in dark. As this time increases, it has been observed that most of the carotenoids degrade. All extraction and work-up procedures were conducted under yellow light to prevent photo-isomerization and degradation of carotenoids.
Saponification of the Extracts

Saponification is mainly reported to be effective for removing colorless contaminating lipids and for destroying the chlorophyll. It also hydrolyzes carotenoid esters. Carotenols esterified with one or more fatty acids are encountered more frequently than are carotenoid carboxylic acid esters. Saponification of carotenol esters is advantageous before submission to HPLC (Britton 1995b). This has the advantage due to concentrating the carotenoids by removal of neutral lipids. In addition, it is also easier to characterize and determine quantitatively the free carotenols than the fatty acid esters that occur (Bechtold and Mussak 2009).

The colored extracts obtained from green microalgae were then pooled in a separatory funnel containing diethyl ether. After gentle shaking, the phases were left to settle and the aqueous phase was removed. This operation should be repeated several times until the upper layer is colorless. The residue obtained was dissolved in $10.0 \mathrm{~mL}$ of diethyl ether for partition followed by the addition of $10.0 \mathrm{~mL}$ of $10.0 \%$ methanolic $\mathrm{KOH}$ solution containing $0.01 \%$ pyrogallol, and saponification was carried out for $2 \mathrm{~h}$ under nitrogen atmosphere. Carotenoids were extracted from the methanolic $\mathrm{KOH}$ phase with $10.0 \mathrm{~mL}$ diethyl ether and $10.0 \mathrm{~mL} 10.0 \% \mathrm{Na}_{2} \mathrm{SO}_{4}$ solution. Addition of the salt stops the reaction and helps the removal of excess alkali. The combined diethyl ether phase was filtered through $0.20 \mu \mathrm{m}$ nylon membrane filter (Sartorius) and concentrated by rotary evaporator at $25.0^{\circ} \mathrm{C}$ under $400 \mathrm{mbar}$. The remaining water was removed with the aid of nitrogen gas. The residue was then dissolved in $10.0 \mathrm{~mL}$ of dichloromethane. The samples were diluted ten times with mobile phase for all-trans-lutein, all-trans-violaxanthin, and 9 or 9 '-cis- $\beta$-carotene. For the other carotenoids, direct analysis was performed without making any dilution.

As a sample volume, $20.0 \mu \mathrm{L}$ was injected for HPLC analysis. The summary of the whole process was designated in Fig. 2.

Analysis of Carotenoids in S. protuberans by HPLC-DAD and LC-APCI-MS

Agilent 1,200 Series HPLC-DAD (USA) system was used for the determination of carotenoids. Prior to use, all HPLC-grade mobile phase solutions were degassed using an ultrasonic bath (Elmasonic $\mathrm{S} 80 \mathrm{H}$,). The reversed-phase column was a YMC Carotenoid $\mathrm{C}_{30}$ column, $250 \times 4.6 \mathrm{~mm}, 5 \mu \mathrm{m}$ (Waters, Milford, MA, USA). The column temperature was set at $25.0^{\circ} \mathrm{C}$. The separation was achieved by gradient elution at a flow rate of $1.0 \mathrm{~mL} / \mathrm{min}$. The injection volume was $20.0 \mu \mathrm{L}$, and detection was made by diode array detector with quantitation at the wavelength of maximum absorption for each analyte in order to improve the response factor. On the other hand, the 


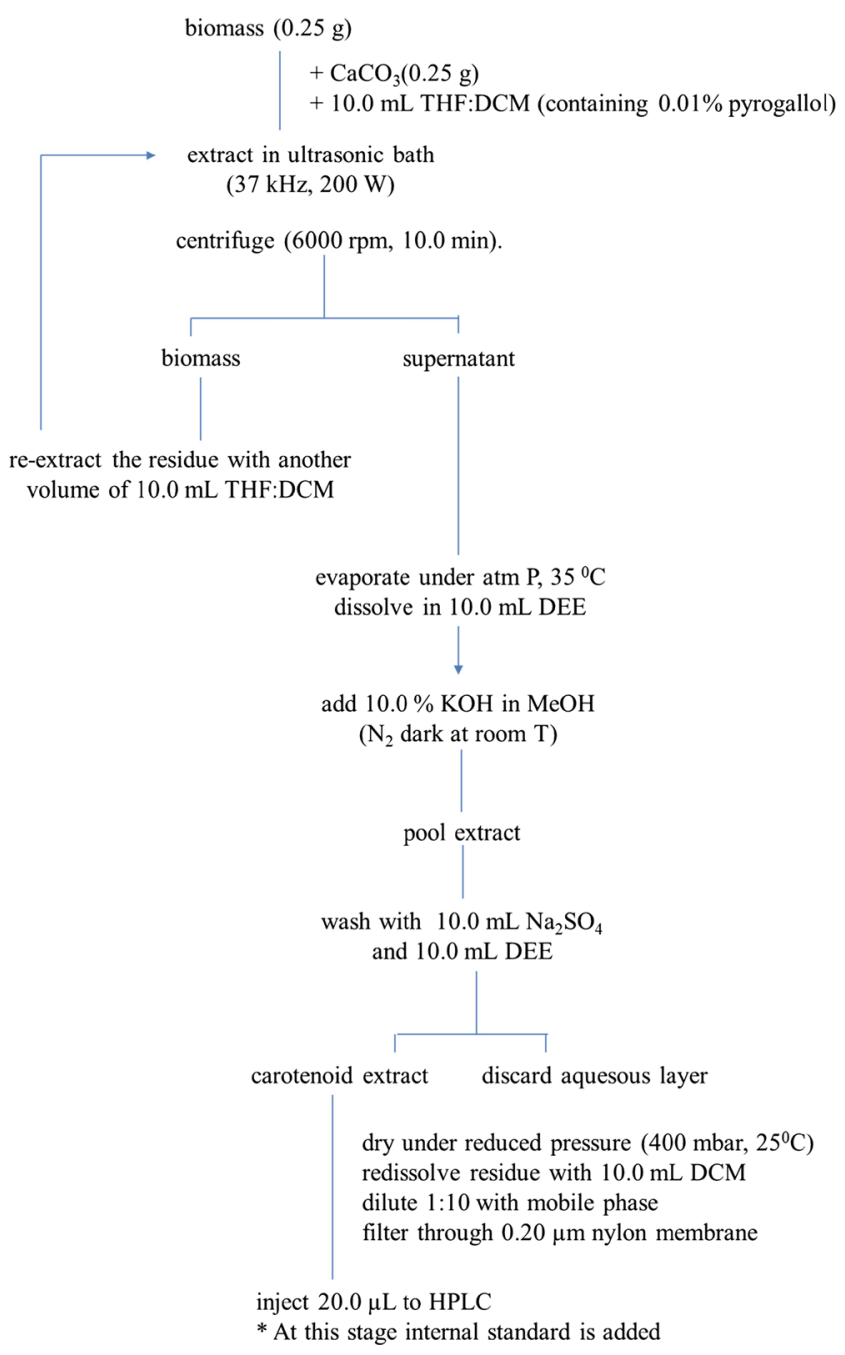

Fig. 2 Summary of the extraction method and saponification procedure for the analysis of carotenoids in the green microalga $S$. protuberans

chromatogram was obtained at $450 \mathrm{~nm}$. The full spectrum from 300 to $600 \mathrm{~nm}$ was also recorded.

In order to obtain mass spectra, AB Sciex 4,000 Q-trap (USA) instrument was used. Positive ion mode (atmospheric pressure chemical ionization (APCI)) was used for the investigation of carotenoids. The total ion current scanning range was $500-700 \mathrm{~m} / z$. The APCI vaporizer was $350{ }^{\circ} \mathrm{C}$. The optimum corona current was $3 \mu \mathrm{A}$ during positive ion APCI.

\section{Calibration Curves}

Due to the light-sensitive nature of carotenoids, stock standard solutions were prepared under yellow light (Philips lamp TLD $36 \mathrm{~W} / 16$ yellow, light transmission at $500-750 \mathrm{~nm}$ ) at room temperature within the shortest possible time. For the preparation of stock carotenoid standards, $5.0 \mathrm{mg}$ of all-trans carotenoid and, for internal standard, $5.0 \mathrm{mg}$ of all-trans- $\beta$-apo- $8^{\prime}$ carotenal were accurately weighed and dissolved in chloroform in separate volumetric flasks $(50.0 \mathrm{~mL})$. Calibration standards $\left(0.020-10.0 \mathrm{mgL}^{-1}\right)$ were prepared from the stock solution and contained a fixed concentration of internal standard $\left(3.0 \mathrm{mgL}^{-1}\right)$. Three replicate measurements were made for each standard solution. All standard and sample solutions were kept in amber-colored volumetric flasks wrapped with aluminum foil after nitrogen flush in order to avoid decomposition of carotenoids. Calibration curves were obtained by plotting the ratio of absorbances of each analyte and the internal standard as a function of analyte concentration. Absorbance values were measured in terms of peak area. It is a great problem that there is no available certified reference standard for each carotenoid. For this reason, in order to check the accuracy of calibration curve, certain concentration of a standard solution (within the limit of linearity) was injected after each sample introduction. Tolerance limit for concentration was under $5 \%$.

\section{Determination of LOD and LOQ}

The detection and quantification limits (limit of detection (LOD) based on $3 \mathrm{~s}$ and limit of quantification (LOQ) based on $10 \mathrm{~s}$, respectively) were determined using the standard deviation of the lowest concentration of the calibration curve. Standard deviation of the response was based on the manually integrated peaks after ten successive injections.

\section{Identification and Determination of Carotenoids in S. protuberans}

For the separation of carotenoids in green microalgae, a gradient system was developed due to its resolving power and improved sensitivity as the isocratic elution took much more time. The mobile phase consisted of a gradient of methanol (A), methyl tert-butyl ether (B) and water (C). The gradient profile of the mobile phase $(\mathrm{A} / \mathrm{B} / \mathrm{C})$ was set at $70: 25: 5$ and changed linearly to $60: 35: 5$ in $5 \mathrm{~min}$, and then it was regulated to $45: 55: 0$ from 5 to $10 \mathrm{~min}$. Finally, the mobile phase was adjusted to 25:75:0 for the last $5 \mathrm{~min}$ (10 to $15 \mathrm{~min}$ ). Internal standard calibration method was applied, and for this purpose, trans-beta-apo-8'carotenal was used. The developed LCDAD method described is fast, specific, and precise for the determination of carotenoids in the green microalga. HPLC chromatogram for S. protuberans was shown in Fig. 3, and the absorption profiles for each carotenoid were depicted in Fig. 4.

In order to get information about the absorption profiles of carotenoids, spectroscopic data were used which were recorded between 300 and $600 \mathrm{~nm}$ using diode array detection (DAD). It presents the absorption spectra for the carotenoid standards and the carotenoids extracted from S. protuberans (supplementary information). In addition, Table 1 shows the DAD spectra required for tentative identification. In order to be sure of good chromatographic separation validation 


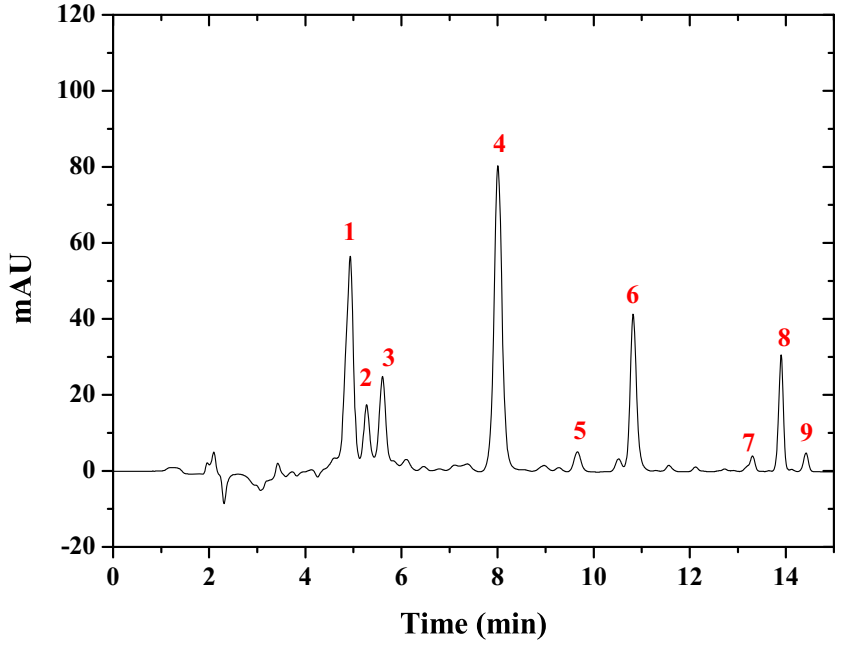

Fig. 3 HPLC chromatogram for S. protuberans obtained at $450 \mathrm{~nm}$

parameters like LOD, LOQ, percent peak purity, capacity factor and selectivity factor should be checked for the proposed method. These values were presented in Table 2 for S. protuberans.
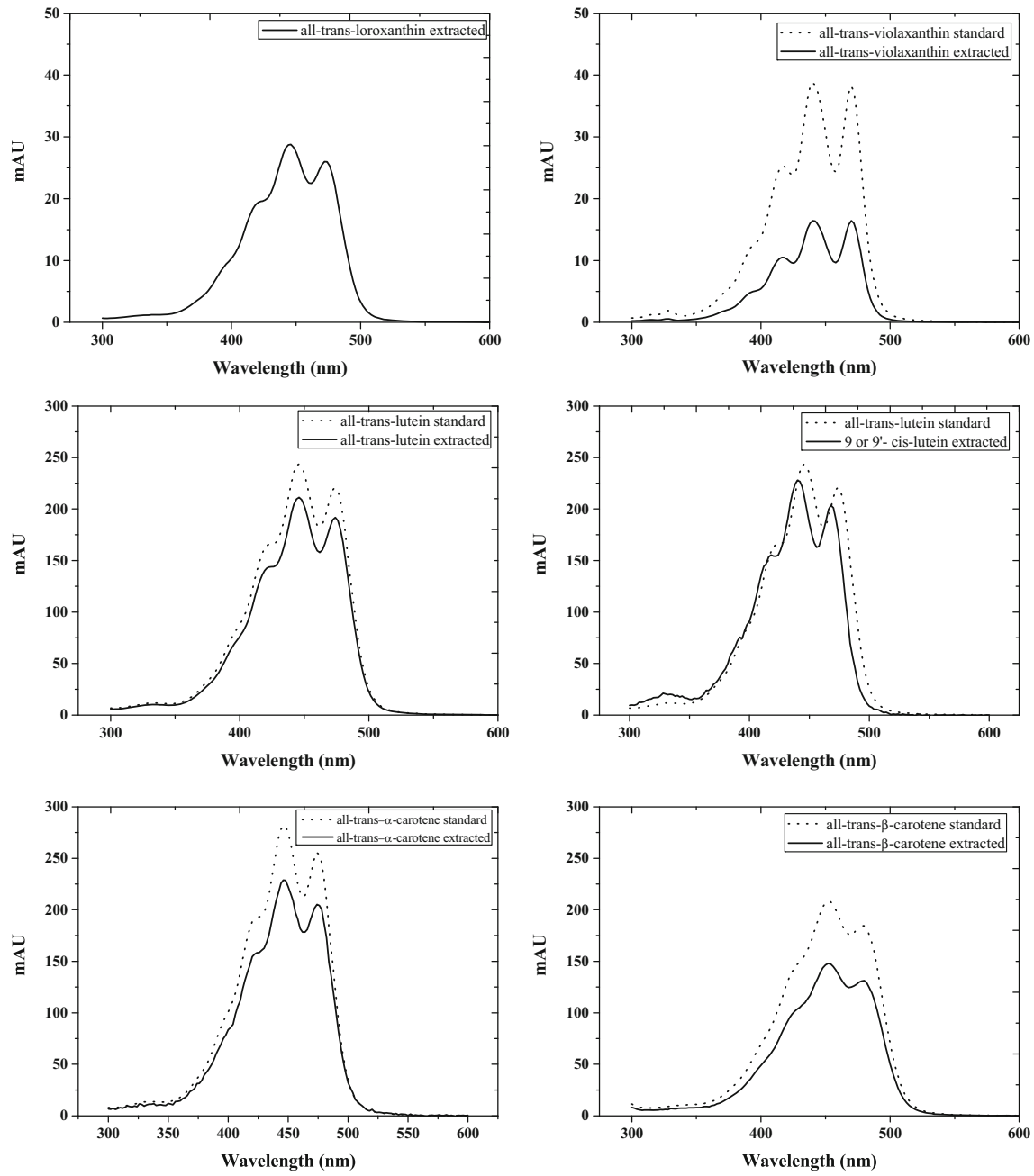

For the identification of carotenoids, spectroscopic data are not enough, and mass spectrum is generally required. For this reason, a mass spectrum of green microalgal extract was obtained. The liquid chromatography-atmospheric pressure chemical ionization-mass spectrometry (LC-APCI-MS) data, which have been used as complementary information of carotenoids, were summarized in Table 3 for S. protuberans.

\section{Results and Discussion}

\section{Composition and Morphology of S. protuberans}

Some of the important factors that may be responsible for the carotenoid contents of a microalga could be its morphology and composition. Chemical nature of substances may differ for each microalgae. For this purpose, the elemental analyses were realized, and according to the results obtained, S. protuberans involves $43.12 \% \mathrm{C}, 5.21 \% \mathrm{~N}, 6.51 \% \mathrm{H}$, and $0.73 \% \mathrm{~S}$ by mass.

Fig. 4 DAD spectra for available carotenoid standards and carotenoids extracted from S. protuberans
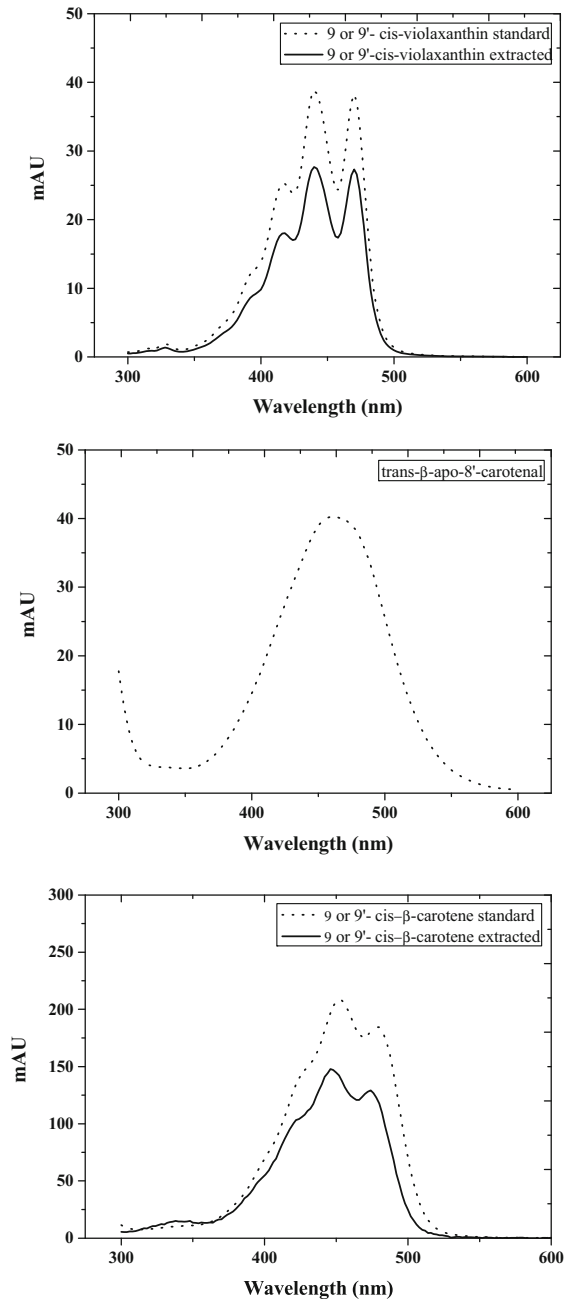
Table 1 UV-visible absorption data for tentative identification of carotenoids in S. protuberans

\begin{tabular}{|c|c|c|c|c|c|c|c|c|c|c|}
\hline \multirow{2}{*}{$\frac{\text { Peak no. }}{1}$} & \multirow{2}{*}{$\begin{array}{l}\text { Compound } \\
\text { All-trans-loroxanthin }\end{array}$} & \multicolumn{3}{|c|}{$\lambda{\text { (reported })^{\mathrm{a}}}^{\mathrm{a}}$} & \multicolumn{3}{|c|}{$\lambda$ (observed) } & \multicolumn{3}{|c|}{$\lambda$ (standards) } \\
\hline & & & 446 & 474 & & 446 & 474 & & & \\
\hline 2 & All-trans-violaxanthin & 419 & 440 & 470 & 417 & 440 & 470 & 418 & 440 & 470 \\
\hline 3 & 9- or 9'-cis-violaxanthin & 414 & 436 & 464 & 418 & 440 & 470 & & & \\
\hline 4 & All-trans-lutein & 422 & 445 & 474 & 423 & 446 & 474 & 424 & 446 & 474 \\
\hline 5 & 9- or 9'-cis-lutein & 420 & 442 & 470 & 418 & 440 & 470 & & & \\
\hline 6 & Internal standard ${ }^{\mathrm{b}}$ & & 458 & & & 456 & & & 456 & \\
\hline 7 & All-trans- $\alpha$-carotene & 423 & 444 & 473 & 423 & 446 & 474 & 423 & 446 & 474 \\
\hline 8 & All-trans- $\beta$-carotene & 428 & 450 & 478 & & 452 & 478 & & 452 & 478 \\
\hline 9 & 9 - or 9'-cis- $\beta$-carotene & 422 & 448 & 474 & 423 & 446 & 474 & 423 & 446 & 474 \\
\hline
\end{tabular}

${ }^{\text {a }}$ Britton et al. 2004 (Reported values are taken according to the results obtained in ethanol since initial mobile phase composition is mainly methanol)

a trans-beta-apo-8'-carotenal

The optical and scanning electron microscope images were designated in Fig. 1. The cell size and shape, in turn, affect the efficient extraction of biomolecules from the species. In order to obtain the carotenoids during the extraction process, the cell wall of the microalga should be destroyed and dissolved in the appropriate solvent. For its destructive power, ultrasoundassisted extraction was used for the extraction of carotenoids from the microalgae. Extraction procedure was followed by a saponification step to simplify the separation of carotenoids. The procedure was briefly presented in Fig. 2.

\section{HPLC-DAD Analysis of Carotenoids in S. protuberans}

According to the chromatogram obtained from S. protuberans, all the carotenoids were well separated from each other using a simple gradient elution method. Xanthophylls were eluted in the first $10 \mathrm{~min}$, and then carotenes were observed.

Due to lack of some carotenoid standards, all-transloroxanthin, 9- or 9'-cis-violaxanthin, and 9- or 9'-cis-lutein could not be quantified. The presence of loroxanthin in S. protuberans has been considered to be relatively high based on its peak area. It has been reported that loroxanthin is produced only by specific green algae (Britton et al. 2004). Therefore, $S$. protuberans might be an alternative source for loroxanthin, and particularly, it could serve as a carotenoid standard.

According to the HPLC chromatogram obtained (Fig. 3), some of the peaks were tentatively identified based on the literature data (Britton 1995b). It has been known that three features of the UV-vis spectrum provide valuable information for structural characterization and quantitative analysis: (1) wavelength of maximum absorption, (2) spectral shape, and (3) intensity of absorption (Britton et al. 2004). Even small differences in their absorption profiles give us an idea about the identity of each carotenoid. For this reason, diode array detector throughout the analysis obtained the absorption spectra of each carotenoid. DAD spectra for available carotenoid standards and carotenoids extracted from S. protuberans were presented in Fig. 4. This data then combined with the values obtained by mass spectrometric data. Table 1 shows the characteristic absorption wavelengths of carotenoids identified for the microalga, which gives important clues about the identification. According to the data, values of carotenoid standards well match with the observed values. The employed chromatographic conditions seemed to separate many of the carotenoid compounds within $15.0 \mathrm{~min}$. Finally, the validation parameters with the proposed LC method were calculated, and the results were shown in Table 2.

\section{Mass Spectrometry of Carotenoids in S. protuberans}

APCI has become the most widely used ionization technique for carotenoids, and most mass spectra of carotenoids have been acquired using positive ion mode. (Hao et al. 2005; Kurz et al. 2008; Rezanka et al. 2009; Rivera et al. 2011; Weller and Breithaupt 2003). The fragment pattern observed in the carotenoid mass spectra depends on the ionization technique and composition of the mobile phase used; characteristic carotenoid fragments have been observed with various ionization techniques. In addition, the removal of a hydroxyl group or a molecule of water $[\mathrm{M}-17]^{+}$or $[\mathrm{M}+\mathrm{H}-18]^{+}$is characteristic of the presence of a hydroxyl group in the compound. These ions have been obtained through EI, ESI, and APCI (van Breemen 1995). Since the fragmentation in chemical ionization is less, the most abundant ions generated are usually the quasimolecular ions $[\mathrm{M}+\mathrm{H}]^{+}$(Britton 1995b). In the present study, $[\mathrm{M}+\mathrm{H}]^{+},[\mathrm{M}+\mathrm{H}-18]^{+}$and $[\mathrm{M}+\mathrm{H}-36]^{+}$ions were easily seen in the mass spectra of green microalga.

In order to help the identification of carotenoids, spectral data obtained from DAD detector were combined with the mass spectra. Hence, possible carotenoids were defined. The LCAPCI-MS data of carotenoids for S. protuberans were compared with the data given in literature as shown in Table 3. Analytical standards were provided for the ones whose mass 
Table 2 Summarized validation parameters with proposed LC method (gradient elution with 70:25:5 MeOH/MTBE/ $\mathrm{H}_{2} \mathrm{O}$ at the wavelength of interest, flow rate, $1.0 \mathrm{~mL} / \mathrm{min}$ ) for $S$. protuberans

\begin{tabular}{|c|c|c|c|c|c|c|c|}
\hline Carotenoids & $\begin{array}{l}\text { LOD } \\
(\mu \mathrm{g} / \mathrm{mL})\end{array}$ & $\begin{array}{l}\text { LOQ } \\
(\mu \mathrm{g} / \mathrm{mL})\end{array}$ & $r^{2}$ & $\begin{array}{l}\text { Peak } \\
\text { purity \% }\end{array}$ & $\begin{array}{l}\text { Capacity } \\
\text { factor (k') }\end{array}$ & $\begin{array}{l}\text { Selectivity } \\
\text { factor }(\alpha)\end{array}$ & $\begin{array}{l}\text { Content } \\
(\mathrm{mg} / \mathrm{g})^{\mathrm{a}}\end{array}$ \\
\hline All-trans-loroxanthin & & No available standard & & 98.9 & 1.43 & 1.00 & ND \\
\hline All-trans-violaxanthin & 0.014 & 0.045 & 0.9998 & 98.7 & 1.59 & 1.11 & 1.45 \\
\hline 9- or 9'-cis-violaxanthin & & No available standard & & 97.6 & 2.15 & 1.21 & ND \\
\hline All-trans-lutein & 0.0032 & 0.011 & 0.9998 & 99.5 & 3.15 & 1.47 & 2.47 \\
\hline 9- or 9'-cis-lutein & & No available standard & & 97.4 & 3.97 & 1.26 & ND \\
\hline All-trans- $\alpha$-carotene & 0.016 & 0.055 & 0.9997 & 98.6 & 5.68 & 1.27 & 0.15 \\
\hline All-trans- $\beta$-carotene & 0.012 & 0.041 & 0.9995 & 99.2 & 6.05 & 1.08 & 0.55 \\
\hline 9 - or $9^{\prime}$-cis- $\beta$-carotene & 0.015 & 0.051 & 0.9995 & 97.4 & 6.25 & 1.03 & 0.20 \\
\hline
\end{tabular}

$N D$ not detected

${ }^{a} \mathrm{RSD}$ values $<5 \%$

values, spectral data, and pattern matched. Finally, the spectral values and retention times were compared with the carotenoids in each chromatogram. However, some of the standards like loroxanthin and some cis-structures of many carotenoids are not available. Therefore, tentative identification has been made.

\section{Method Validation for Extraction and Saponification} of Carotenoids in S. protuberans

For the validation of extraction/saponification of carotenoids, the same procedure was applied by using Certified Reference Material (CRM) (BCR 485-mixed vegetables). The criterion to consider a good agreement was the accuracy of the process for extraction and saponification. Literature studies show that there are a few number of standard or certified reference materials for the method validation of carotenoids. Most of them are limited in terms of content and matrix (Dias et al. 2010; Kimura et al. 2007). In addition, some of them are no longer produced. Plant extract is thought to be the most relevant material with the microalgal extract, and therefore, a certified reference material, BCR 485 (CRM-mixed vegetables), was used for the validation of our method. According to the analyses performed, the results obtained are consistent with CRM values of the carotenoids present in the sample. The results can be examined in Table 4 .

\section{Conclusions}

In recent years, there has been particular emphasis on obtaining accurate data on carotenoids that are reliable since they are important for various health and nutrition activities. On the other hand, significant attention has recently been drawn to the use of microalgae since they can produce carotenes and xanthophylls in rich amounts. For this reason, carotenoid production has become one of the most successful branches in biotechnology of microalgae.

Another problem associated with analysis of carotenoids is the difficulty in obtaining standard compounds. Therefore our

Table 3 LC-APCI-MS (positive mode) data of carotenoids in S. protuberans

\begin{tabular}{|c|c|c|c|c|}
\hline $\begin{array}{l}\text { Peak } \\
\text { no. }\end{array}$ & Carotenoid & $m / z$ (reported) $)^{\mathrm{a}}$ & $m / z$ (observed) & ( $m / z$ standards $)$ \\
\hline 1 & All-trans-loroxanthin & $\begin{array}{l}584[\mathrm{M}]^{+}, 566\left[\mathrm{M}-\mathrm{H}_{2} \mathrm{O}\right]^{+} \\
548\left[\mathrm{M}-2 \mathrm{H}_{2} \mathrm{O}\right]^{+}\end{array}$ & $\begin{array}{l}585.5[\mathrm{M}+\mathrm{H}]^{+}, 567.4\left[\mathrm{M}+\mathrm{H}-\mathrm{H}_{2} \mathrm{O}\right]^{+}, \\
549.5\left[\mathrm{M}+\mathrm{H}-2 \mathrm{H}_{2} \mathrm{O}\right]^{+}\end{array}$ & \\
\hline 2 & All-trans-violaxanthin & $\begin{array}{l}600[\mathrm{M}]^{+}, 582\left[\mathrm{M}-\mathrm{H}_{2} \mathrm{O}\right]^{+} \\
508[\mathrm{M}-92]^{+}\end{array}$ & $\begin{array}{l}601.5[\mathrm{M}+\mathrm{H}]^{+}, 583.5\left[\mathrm{M}+\mathrm{H}-\mathrm{H}_{2} \mathrm{O}\right]^{+}, \\
509.4[\mathrm{M}+\mathrm{H}-92]^{+}\end{array}$ & $601.5,583.5,509.4$ \\
\hline 3 & 9- or 9'-cis-violaxanthin & $600[\mathrm{M}]^{+}$ & $601.5[\mathrm{M}+\mathrm{H}]^{+}$ & \\
\hline 4 & All-trans-lutein & $569[\mathrm{M}]^{+}, 550\left[\mathrm{M}-\mathrm{H}_{2} \mathrm{O}\right]^{+}$ & $569.5[\mathrm{M}+\mathrm{H}]^{+}, 551.5\left[\mathrm{M}+\mathrm{H}-\mathrm{H}_{2} \mathrm{O}\right]^{+}$ & $569.5,551.5$ \\
\hline 5 & 9- or 9'-cis-lutein & $568[\mathrm{M}]^{+}$ & $569.5[\mathrm{M}+\mathrm{H}]^{+}$ & \\
\hline 7 & All-trans- $\alpha$-carotene & $536[\mathrm{M}]^{+}, 518\left[\mathrm{M}-\mathrm{H}_{2} \mathrm{O}\right]^{+}$ & $537.4[\mathrm{M}+\mathrm{H}]^{+}, 519.4\left[\mathrm{M}+\mathrm{H}-\mathrm{H}_{2} \mathrm{O}\right]^{+}$ & $537.4,519.4$ \\
\hline 8 & All-trans- $\beta$-carotene & $536[\mathrm{M}]^{+}, 518\left[\mathrm{M}-\mathrm{H}_{2} \mathrm{O}\right]^{+}$ & $537.4[\mathrm{M}+\mathrm{H}]^{+}, 519.4\left[\mathrm{M}+\mathrm{H}-\mathrm{H}_{2} \mathrm{O}\right]^{+}$ & $537.4,519.4$ \\
\hline 9 & 9 - or $9^{\prime}$-cis- $\beta$-carotene & $536[\mathrm{M}]^{+}, 518\left[\mathrm{M}-\mathrm{H}_{2} \mathrm{O}\right]^{+}$ & $537.4[\mathrm{M}+\mathrm{H}]^{+}, 519.4\left[\mathrm{M}+\mathrm{H}-\mathrm{H}_{2} \mathrm{O}\right]^{+}$ & $537.4,519.4$ \\
\hline
\end{tabular}

${ }^{\text {a }}$ Britton et al. 2004 
Table 4 Method validation results for some carotenoids using BCR 485 (CRM-mixed vegetables)

\begin{tabular}{lll}
\hline Carotenoids & $\begin{array}{l}\text { Reported carotenoid } \\
\text { values in mixed } \\
\text { vegetables BCR 485 } \\
(\mathrm{mg} / \mathrm{kg})\end{array}$ & $\begin{array}{l}\text { Carotenoid values } \\
\text { obtained using } \\
\text { proposed method } \\
(\mathrm{mg} / \mathrm{kg})^{\mathrm{a}}\end{array}$ \\
\hline All-trans-lutein & $12.5 \pm 0.8$ & $12.6 \pm 0.2$ \\
All-trans- $\alpha$-carotene & $10.5 \pm 0.6$ & $10.5 \pm 0.5$ \\
All-trans- $\beta$-carotene & $23.7 \pm 1.5$ & $23.7 \pm 0.9$ \\
\hline
\end{tabular}

${ }^{\text {a }}$ Method validation was performed using BCR 485 according to the proposed extraction and saponification procedure $(n=3)$

study also emphasized that the identification and determination of carotenoids from new sources are required. Based on this study, it could be proposed that loroxanthin from $S$. protuberans can be a good alternative as an analytical standard.

In this work, a new extraction method was applied, and an HPLC-DAD method was developed to separate the carotenoids in $S$. protuberans by employing a $\mathrm{C}_{30}$ column with a simple gradient elution. The analytical results showed that the method was fast, relatively simple, and applicable. Spectroscopic and mass spectrometric data were linked to investigate the carotenoids. In conclusion, the future of microalgal biotechnology seems very promising, and the microalgae has great potential for carotenoid products.

Acknowledgments The authors would like to acknowledge The Scientific and Technological Research Council of Turkey for the support of this work through the project TBAG 110 T099 and the Center of Material's Research at İzmir Institute of Technology for the facilities (SEM and Elemental Analyzer) as well as Spektrotek A.Ș. for the mass analyses (LC-APCI-MS).

Conflict of Interest Ayşegül Erdoğan has received research grants from The Scientific and Technological Research Council of Turkey and speaker honorarium from The Scientific and Technological Research Council of Turkey, and declares that she has no conflict of interest. Ali Çağır declares that he has no conflict of interest. Meltem Conk Dalay has received research grants from The Scientific and Technological Research Council of Turkey, and declares that she has no conflict of interest. Ahmet E. Eroğlu declares that he has no conflict of interest. This article does not contain any studies with human or animal subjects.

\section{References}

Andersen RA (2005) Algal culturing techniques. Access Online via Elsevier

Bechtold T, Mussak R (2009) Handbook of natural colorants. John Wiley \& Sons

Borowitzka MA (1995) Microalgae as sources of pharmaceuticals and other biologically active compounds. J Appl Phycol 7:3-15

Britton G, Liaaen-Jensen S, Pfander HP (1995a) Caroteniods: Volume 1B: Spectroscopy. Birkhiiuser Verlag, Boston

Britton G, Liaaen-Jensen S, Pfander HP (1995b) Carotenoids, Vol. 1A: Isolation and Analysis. Eds., Birkhäuser, Basel
Britton G, Liaaen-Jensen S, Pfander HP (2004) Carotenoids: Handbook. Springer,

Carmona ML, Naganuma T, Yamaoka Y (2003) Identification by HPLCMS of carotenoids of the Thraustochytrium $\mathrm{CHN}-1$ strain isolated from the Seto Inland Sea. Biosci Biotechnol Biochem 67:884-888

Christaki E, Karatzia M, Bonos E, Florou-Paneri P, Karatzias C (2012) Effect of dietary Spirulina platensis on milk fatty acid profile of dairy cows. Asian J Anim Vet Adv 7:597-604

Dias MG, Oliveira L, Camões M, Nunes B, Versloot P, Hulshof PJ (2010) Critical assessment of three high performance liquid chromatography analytical methods for food carotenoid quantification. $\mathrm{J}$ Chromatogr A 1217:3494-3502

Fabregas J, Dominguez A, Regueiro M, Maseda A, Otero A (2000) Optimization of culture medium for the continuous cultivation of the microalga Haematococcus pluvialis. Appl Microbiol Biotechnol 53:530-535

Fraser PD, Bramley PM (2004) The biosynthesis and nutritional uses of carotenoids. Prog Lipid Res 43:228-265. doi:10.1016/j.plipres. 2003.10.002

Guedes AC, Amaro HM, Malcata FX (2011) Microalgae as sources of carotenoids. Mar Drugs 9:625-644

Hao Z, Parker B, Knapp M, Yu LL (2005) Simultaneous quantification of $\alpha$-tocopherol and four major carotenoids in botanical materials by normal phase liquid chromatography-atmospheric pressure chemical ionization-tandem mass spectrometry. J Chromatogr A 1094:8390

Inbaraj BS, Lu H, Hung C, Wu W, Lin C, Chen B (2008) Determination of carotenoids and their esters in fruits of $<\mathrm{i}>$ Lycium barbarum $</ \mathrm{i}>$ Linnaeus by HPLC-DAD-APCI-MS. J Pharm Biomed Anal 47: 812-818

Kimura M, Kobori CN, Rodriguez-Amaya DB, Nestel P (2007) Screening and HPLC methods for carotenoids in sweetpotato, cassava and maize for plant breeding trials. Food Chem 100:1734-1746

Kotake-Nara E, Nagao A (2011) Absorption and metabolism of xanthophylls. Mar Drugs 9:1024-1037

Kurz C, Carle R, Schieber A (2008) HPLC-DAD-MS $<$ sup $>$ n $</$ sup $>$ characterisation of carotenoids from apricots and pumpkins for the evaluation of fruit product authenticity. Food Chem 110:522-530

Ladislav F, Vera P, Karel S, Karel V (2005) Reliability of carotenoid analyses. A Rev Curr Anal Chem 1:93-102

Landrum JT (2010) Carotenoids: physical, chemical, and biological functions and properties. CRC Press, Boca Raton, FL

Maiani G et al (2009) Carotenoids: actual knowledge on food sources, intakes, stability and bioavailability and their protective role in humans. Mol Nutr Food Res 53:S194-S218

Maoka T, Fujiwara Y, Hashimoto K, Akimoto N (2002) Rapid identification of carotenoids in a Combination of liquid Chromatography/ UV-visible absorption Spectrometry by photodiode-array detector and atmospheric pressure chemical ionization mass spectrometry (LC/PAD/APCI-MS). J Oleo Sci 51:1-9

Olaizola M (2003) Commercial development of microalgal biotechnology: from the test tube to the marketplace. Biomol Eng 20:459-466. doi:10.1016/S1389-0344(03)00076-5

Rao AV, Rao LG (2007) Carotenoids and human health. Pharmacol Res 55:207-216. doi:10.1016/j.phrs.2007.01.012

Rehbein J et al (2007) Characterization of bixin by LC-MS and LCNMR. J Sep Sci 30:2382-2390

Rezanka T, Olsovska J, Sobotka M, Sigler K (2009) The use of APCI-MS with HPLC and other separation techniques for identification of carotenoids and related compounds. Curr Anal Chem 5:1-25

Rivera S, Vilaró F, Canela R (2011) Determination of carotenoids by liquid chromatography/mass spectrometry: effect of several dopants. Anal Bioanal Chem 400:1339-1346

Rivera SM, Canela-Garayoa R (2012) Analytical tools for the analysis of carotenoids in diverse materials. J Chromatogr A 1224:1-10. doi:10. 1016/j.chroma.2011.12.025 
Sivathanu B, Palaniswamy S (2012) Purification and characterization of carotenoids from green algae Chlorococcum humicola by HPLCNMR and LC-MS-APCI. Biomed Prev Nutr 2:276-282. doi:10. 1016/j.bionut.2012.04.006

Spolaore P, Joannis-Cassan C, Duran E, Isambert A (2006) Commercial applications of microalgae. J Biosci Bioeng 101:87-96

Takaichi S (2011) Carotenoids in algae: distributions, biosyntheses and functions. Mar Drugs 9:1101-1118

Tian Q, Duncan CJ, Schwartz SJ (2003) Atmospheric pressure chemical ionization mass spectrometry and in-source fragmentation of lutein esters. J Mass Spectrom 38:990-995 van Breemen RB (1995) Electrospray liquid chromatography-mass spectrometry of carotenoids. Anal Chem 67:2004-2009

van Breemen RB (1997) Liquid chromatography/mass spectrometry of carotenoids. Pure Appl Chem 69:2061-2066

van Breemen RB, Dong L, Pajkovic ND (2012) Atmospheric pressure chemical ionization tandem mass spectrometry of carotenoids. Int J Mass Spectrom 312:163-172. doi:10.1016/j.ijms.2011. 07.030

Weller P, Breithaupt DE (2003) Identification and quantification of zeaxanthin esters in plants using liquid chromatography-mass spectrometry. J Agric Food Chem 51:7044-7049 